\title{
EDUCAÇÃO EM DIREITOS HUMANOS E RAP: VOZES PERIFÉRICAS NO ESPAÇO ESCOLAR
}

\author{
EDUCATION IN HUMAN RIGHTS AND RAP: PERIPHERAL VOICES AT THE SCHOOL \\ AMBIENCE
}

\author{
EDUCACIÓN EN DERECHOS HUMANOS Y RAP: VOCES PERIFÉRICAS \\ EN EL ESPACIO ESCOLAR
}

Jonas de Souza Gonsalgo1

Cilene Margarete Pereira²

\begin{abstract}
RESUMO
$\mathrm{Na}$ educação básica, a abordagem dos direitos humanos passa efetivamente pela exploração de temas relativos à exclusão/inclusão social de grupos sociais minoritários. Além de promover o acesso a conhecimentos oficiais e tradicionais, a escola é o espaço também de saberes e de grupos outros, distanciados de instâncias decisórias, fazendo-se necessário, para a real educação em direitos humanos, reverberar suas existências na cultura escolar. Para tanto, propomos que o rap seja levado para a sala de aula como um gênero poético-musical originário de territórios periféricos e constituído por estes sujeitos, visto que aponta para um lugar de falar envolto em saberes de pessoas marginalizadas, conferindo voz/poder a grupos historicamente silenciados. Tal perspectiva se alinha à Base Nacional Comum Curricular (BRASIL, 2018), no que diz respeito à diversidade social e de saberes, ao exercício da empatia e da solidariedade e à responsabilidade e cidadania, conforme disposto nas competências gerais 6, 9 e 10. Para tanto, este artigo apresenta alguns pontos fundamentais do gênero poético-musical rap, com o fim de instrumentalizar professores e alunos para sua discussão em sala de aula, evidenciando sua estrutura composicional (forma e temas) e sua relação com saberes periféricos e grupos sociais marginalizados, por meio de algumas das letras de suas canções.
\end{abstract}

PALAVRAS-CHAVE: Educação. Direitos humanos. Rap. Periferias.

\begin{abstract}
In basic education, the approach to themes connected to human rights goes effectively through the analysis of subjects related to the inclusion/exclusion of minority social groups. School is also the ambience for knowledge promotion and for other groups, apart from the decision-making bodies, making it necessary for real education on human rights to reverberate their existence within the school culture. Thus, we propose that the rap be taken to the classroom as a musical-poetic genre originated from the periphery and constituted by these people, as it points at a speaking manner that is typical of marginalized groups, giving them voice/power to people historically silenced. Such perspective is aligned to the BNCC (BRAZIL, 2018r), concerning social and knowledge diversity, to the exercise of empathy and solidarity and the responsibility and citizenship, as disposed on the general competences 6,9 and 10. For such, this study presents some fundamental points of the musical-poetic genre rap, aiming at enabling teachers and students for classroom discussion, highlighting its composition structure (shape and themes) and its relation with the peripheral knowledge and marginalized social groups, through some of their lyrics.
\end{abstract}

KEY WORDS: Education. Human Rights. Rap. Periphery.

\footnotetext{
1 Mestrando em Gestão, Planejamento e Ensino pela Universidade Vale do Rio Verde (UninCor). E-mail: jonassgonsalgos@gmail.com

2 Doutora em Teoria e História Literária pela Universidade Estadual de Campinas (UNICAMP). E-mail: cilene.margarete.pereira@gmail.com
} 


\section{RESUMEN}

En la educación básica, el enfoque de las cuestiones de derechos humanos implica efectivamente la exploración de cuestiones relacionadas con la exclusión/inclusión social de los grupos sociales minoritarios. La escuela es el espacio para la promoción del conocimiento y otros grupos, alejados de los órganos de toma de decisiones, haciendo necesario, para una verdadera educación en derechos humanos, reverberar su existencia en la cultura escolar. Por lo tanto, proponemos que el rap sea llevado al aula como un género poético-musical originario de territorios periféricos y constituido por estos temas, ya que apunta a un lugar de habla envuelto en el conocimiento de las personas marginadas, dando voz/poder a las personas históricamente silenciadas. Esta perspectiva está de acuerdo con la Base Común De Currículo Nacional (BRASIL, 2018), con respecto a la diversidad social y el conocimiento, el ejercicio de la empatía y la solidaridad y la responsabilidad y la ciudadanía, según lo dispuesto en las competencias generales 6,9 y 10. Por lo tanto, este artículo presenta algunos puntos fundamentales del género de rap poético-musical, con el fin de instrumentalizar a profesores y estudiantes para la discusión en el aula, evidenciando su estructura compositiva (forma y temas) y su relación con el conocimiento periférico y grupos sociales marginados, a través de algunas de las letras de sus canciones.

PALABRAS CLAVE: Educación. Derechos humanos. El rap. Periferias.

\section{CONSIDERAÇÕES INICIAIS}

A educação em direitos humanos diz respeito a atividades educativas com 0 fim de promover a capacitação e o acesso a informações "orientadas para criar uma cultura universal de direitos humanos", pensando que uma "educação integral em direitos humanos não somente proporciona conhecimentos sobre os direitos humanos e os mecanismos para protegê-los, mas que, além disso, transmite as aptidões necessárias para promover, defender e aplicar os direitos humanos na vida cotidiana." (UNESCO, 2006, p. 1).

No ambiente escolar, sobretudo da educação básica, a abordagem de temas ligados aos Direitos Humanos passa efetivamente, portanto, pela exploração de temas relativos à exclusão/inclusão social destes grupos. Essa discussão é amparada por diversos documentos educacionais, tais como o Decreto 7037/2009, o Parecer CNE/CP 8/2012, a Resolução CNE/CP 1/2012 e as Leis 10.639/2003 e 11.645/2008, que apontam a obrigatoriedade da educação das relações ético-raciais e ensino de história e cultura afro-brasileira e indígena nas escolas.

A proposição deste artigo se associa ao contexto acima, na medida que defende que a escola é o espaço da promoção de saberes e de grupos outros, distanciados de instâncias decisórias, fazendo-se necessário, para a real educação em direitos humanos, reverberar suas existências na cultura escolar. Para tanto, propomos que o rap seja levado para a sala de aula como um gênero poético-musical originário de territórios periféricos e constituído por estes sujeitos, visto que aponta para um lugar de falar envolto em saberes de pessoas marginalizadas, conferindo voz/poder a pessoas historicamente silenciadas. Tal perspectiva se alinha a Base Nacional Comum Curricular (BRASIL, 2018), no que diz respeito à diversidade social e de 
saberes, ao exercício da empatia e da solidariedade e à responsabilidade e cidadania, conforme disposto nas competências gerais 6, 9 e 10 .

Assim, este artigo apresenta alguns pontos fundamentais do gênero poético-musical rap, com o fim de instrumentalizar professores e alunos para sua discussão em sala de aula, evidenciando sua estrutura composicional (forma e temas) e sua relação com saberes periféricos e grupos sociais marginalizados, por meio de algumas das letras de suas canções.

\section{EDUCAÇÃO EM DIREITOS HUMANOS, RAP E PERIFERIAS}

Em 2004, a Organização das Nações Unidas para a Educação, a Ciência e a Cultura (UNESCO) estabeleceu um Programa Mundial para Educação em Direitos Humanos (PMEDH), organizado em três fases. Na primeira fase do programa, compreendida entre os anos de $2005 \mathrm{e}$ 2009, a instituição objetivava formar agentes envolvidos na educação básica (alunos, professores e gestores) para a construção e fortalecimento de uma cultura dos direitos humanos, para "Promover a inclusão e a prática dos direitos humanos nos sistemas de ensino primário e secundário" (UNESCO, 2006, p. 16). ${ }^{3}$ A educação em direitos humanos diz respeito, portanto, a atividades educativas com 0 fim de promover a capacitação e 0 acesso a informações "orientadas para criar uma cultura universal de direitos humanos", pensando que uma "educação integral em direitos humanos não somente proporciona conhecimentos sobre os direitos humanos e os mecanismos para protegê-los, mas que, além disso, transmite as aptidões necessárias para promover, defender e aplicar os direitos humanos na vida cotidiana." (UNESCO, 2006, p. 1).

Trata-se, nesse caso, de pensar uma educação alicerçada, portanto, na valorização daquilo que contorna o próprio conceito de direitos humanos, o princípio da dignidade humana:

[...] o que se convencionou chamar "direitos humanos" são exatamente os direitos correspondentes à dignidade dos seres humanos. São direitos que possuímos não porque 0 Estado assim decidiu, através de suas leis, ou porque nós mesmos assim 0 fizemos, por intermédio dos nossos acordos. Direitos humanos, por mais pleonástico que isso possa parecer, são direitos que possuímos pelo simples fato de que somos humanos. (RABENHORST, 2007 , p. 5 , aspas do autor)

\footnotetext{
3 A segunda (2010-2014) e a terceira fase (2015-2019) tinham como público alvo agentes do Ensino Superior e educadores em geral, servidores públicos e da segurança (polícias e agentes penitenciários) e professionais da mídia, respectivamente. Disponível em: http://www.dhnet.org.br/dados/textos/edh/br/plano_acao_programa_mundial_edh_pt.pdf. Acesso em 20 de jan. 2021.
} 
Magendzo, ao referir-se à educação em direitos humanos, aponta alguns fundamentos essenciais, como a ideia de transformação social, ancorada na necessidade de valorização e visibilidade de grupos excluídos das esferas de poder, para que estes consigam ascensão em espaços públicos decisórios, demandando novas políticas públicas e de bem estar social. (Cf. MAGENDZO, 2016, p. 221).

No ambiente escolar, sobretudo da educação básica, a abordagem de temas ligados aos Direitos Humanos passa efetivamente, portanto, pela exploração de temas relativos à exclusão/inclusão social destes grupos. Essa discussão é amparada por diversos documentos educacionais, tais como o Decreto 7037/2009, o Parecer CNE/CP 8/2012, a Resolução CNE/CP $1 / 2012$ e as Leis 10.639/2003 e 11.645/2008, que apontam a obrigatoriedade da educação das relações ético-raciais e ensino de história e cultura afro-brasileira e indígena nas escolas.

Para que haja a valorização das histórias e vozes de grupos sociais excluídos e silenciados no espaço social, é preciso que a escola (um espaço de socialização e de aprendizagem do mundo) promova um debate eficaz sobre processos de exclusão, assim como está previsto no Parecer 15/1998, referente às Diretrizes Curriculares Nacionais do Ensino Médio (BRASIL, 1998), na ideia de "política da igualdade", que deve ser "inspiradora do ensino em todos os conteúdos curriculares", tornando conteúdo "[...] temas dos direitos da pessoa humana, do respeito, da responsabilidade e da solidariedade, e sempre que os significados dos conteúdos curriculares se contextualizarem nas relações pessoais e práticas sociais convocatórias da igualdade". (BRASIL, 1998, p. 19).

A proposição deste artigo se associa ao contexto acima, na medida que defende que a escola é o espaço da promoção de saberes e grupos outros, distanciados de instâncias decisórias, fazendo-se necessário, para a real educação em direitos humanos, reverberar suas existências na cultura escolar. A pergunta que se faz é a seguinte: sujeitos periféricos se reconhecem como protagonistas e têm sua cultura valorizada no espaço escolar? É provável que essa pergunta seja respondida, se questionado cada aluno de uma escola periférica do país, por negativas - ainda que haja iniciativas que procurem romper com essa dinâmica de exclusão.

Se queremos, de fato, educar para os direitos humanos, é preciso reconhecer, portanto, a escola como um aparelho ideológico das elites (Cf. ALTHUSSER, 1980), que age a partir da ideia de seleção, fazendo com que se retirem dela aqueles que são diferentes e não se enquadram em modelos e padrões culturais, operando, a escola, pela chamada "exclusão pelo sentido", já que "muitos alunos não encontram na escola um sentido para a sua frequência, quer 
ao nível do saber partilhado, quer ao nível da sua utilidade social, quer ainda como quadro de vida" (BARROSO, 2003, p. 27).

A partir das considerações acima, propomos que o rap seja levado para a sala de aula como um gênero poético-musical originário de territórios periféricos e constituído por sujeitos periféricos, visto que aponta para um lugar de falar que se constrói por meio de saberes de sujeitos periféricos e marginalizados, conferindo voz/poder a estes sujeitos historicamente silenciado. Tal perspectiva se alinha a Base Nacional Comum Curricular (BRASIL, 2018), no que diz respeito à diversidade social e de saberes, ao exercício da empatia e da solidariedade e à responsabilidade e cidadania, conforme disposto nas competências gerais 6, 9 e 10 .

Assim, este artigo apresenta alguns pontos fundamentais do gênero poético-musical rap, com o fim de instrumentalizar professores e alunos para sua discussão em sala de aula, evidenciando sua estrutura composicional (forma e temas) e sua relação com saberes periféricos e grupos sociais marginalizados. Além disso, defende-se, aqui, o rap como instrumento de promoção de uma educação crítica e problematizadora, na medida em que descortina aspectos da formação de nossa país, construído por meio de processos de violência. Pelegrini, a respeito de temário de nossa literatura, aponta que

[...] a história brasileira, transposta em temas literários, comporta uma violência de múltiplos matizes, tons e semitons, que pode ser encontrada assim desde as origens, tanto em prosa quanto em poesia: a conquista, a ocupação, a colonização, o aniquilamento dos índios, a escravidão, as lutas pela independência, a formação das cidades e dos latifúndios, os processos de industrialização, o imperialismo, as ditaduras... (PELEGRINI, 2005, p. 134).

Ou seja, a violência é a base constitutiva de nosso país como nação, e se aparece com frequência nas letras de rap é porque este fala de uma realidade histórico-social que se liga a processos de violência e desigualdades, marcados no povo negro pela escravidão.

O rap é um dos elementos que formatam o movimento hip hop. Nas letras desse gênero poético-musical se reverbera e tematiza questões sociais emergentes, como o racismo, discriminações, desigualdades e múltiplas violências, fazendo muitas vezes com que os rappers atuem como ativistas sociais:

Os rappers extrapolam as fronteiras da composição/expressão musical e se dedicam a atividades direcionadas às populações de seus bairros e da periferia urbana em geral. Campanhas informais de arrecadação de mantimentos, oficinas de rap para 
jovens, palestras e debates em escolas e instituições prisionais, organização para trabalho institucionalizado, inserção em partidos políticos e vinculação a movimentos sociais estão entre essas atividades [...] (LOUREIRO, 2015, p. 15).

Dentre os quatro elementos constitutivos do hip hop (o rapper, o DJ, o grafite e a dança), haveria um quinto, o conhecimento,

[...] componente extremamente importante, na medida em que o fator estruturante da estética hip hop brasileira é a questão do ativismo, da consciência de sua história, da afirmação da história de uma cultura local e de suas raízes raciais e, portanto, da necessidade da busca de informação e de conhecimento (HOLLANDA, 2012, p. 87).

O conhecimento da cultura hip hop se dá em diversas formas, sendo uma delas a compreensão da realidade de uma forma histórica, fazendo um atravessamento na diáspora negra no mundo por meio de uma educação não formal, visto que o formal sempre silenciou 0 conhecimento e a ancestralidade do povo negro:

\begin{abstract}
Nesse momento os rappers enfatizam que o "autoconhecimento" é estratégico no sentido de compreender a trajetória da população negra na América e no Brasil. Livros como Negras raízes (Alex Haley), Escrevo o que eu quero (Steve Byko), biografias de Martin Luther King e Malcom X, a especificidade do racismo brasileiro, especialmente discutida por Joel Rufino e Clóvis Moura, bem como lutas políticas da população negra, passaram a integrar a bibliografia dos rappers. 0 objetivo era obter um conhecimento fundamental para a ação, mas que lhes fora negado no processo de educação formal (SILVA, 1999, p. 29).
\end{abstract}

Os rappers são sujeitos que buscam o conhecimento de uma forma autônoma, conhecimento que não foi passado pelo modelo educacional formal e que deixou algumas lacunas no que se refere ao entendimento de uma sociedade pautada no apagamento histórico da re(existência) negra. Compreender essas questões que foram silenciadas é fundamental para que se possa refletir, em sala de aula, sobre aspectos constitutivos da sociedade, como, por exemplo, o racismo, e se contrapor a esse modelo que exclui socialmente determinados sujeitos. Isso fez com que os rappers assumissem uma função social e política, e o rap se convertesse em uma voz dissonante que aclara a realidade histórico-social do país, sendo, portanto, um "raio $\mathrm{x}$ do Brasil".

Assim, uma das funções sociais do rap é narrar acontecimentos, conscientizar, denunciar e propor reflexões que abarcam a realidade dos sujeitos e de sua comunidade, 
indivíduos que em sua maioria são negros e moradores de periferia. Esses indivíduos, em muitos contextos, são historicamente excluídos e marginalizados, devido a sua cultura e seu lócus social, a periferia.

O termo periferia remete ao local que está longe do centro, um lugar que está à margem e distante da centralidade, carente de múltiplos recursos, até mesmo os básicos, como são, por exemplo, as favelas. Ainda que estejam localizadas em áreas nobres das cidades, como acontece no Rio de Janeiro com comunidades como Pavão, Pavãozinho, Babilônia, Morro Dona Marta, etc. (só para citar alguns exemplos), estas favelas estão apartadas de fato da vida pública da cidade, deslocadas de seu centro de poder. Nesse caso, são regiões periféricas que lembram os quilombos.

Campos observa que a "favela é um espaço excluído, assim como eram os quilombos, vítima de uma forte repressão do estado, que trata as comunidades como 'espaços criminalizados' onde todos são suspeitos até que se prove o contrário.". Assim, há, na perspectiva do ensaísta, uma "segregação sócio-espacial [que] é parte visível do estigma da discriminação e do preconceito contra a população das favelas que, em sua maioria, é constituída de pretos e pardos."4

Essa aproximação histórica entre quilombos e favelas se converge em muitos momentos, seja pela carência de múltiplos recursos, seja pela exclusão que esses sujeitos vivenciam cotidianamente, além da criminalização do espaço por meio de agentes do Estado. 0 Estado visualiza esses espaços não como um "problema social" que precisa ser enfrentado com políticas públicas de inserção social e de promoção de direitos; pelo contrário, essas questões são invisibilizadas e muitas vezes não debatidas, promovendo o esquecimento desses locais e das pessoas que ali residem. No entanto, o Estado designa uma "visão especial" para esses locais, representada pela ação da força policial, como vemos com frequência nas letras de rap.

\footnotetext{
Dizem que quando seus amigos morrem

Viram estrelas (sobem)

Peça que olhem (ore), nunca ignorem

Oro calado e os guardo em olhares mariados

Onde pupila são barcos desnorteados

Massa no ar, cápsulas no chão

Cães fitam, mães gritam, não (meu filho, não!)

É o corpo na vala, a bala vem de quem te deve proteção

Fria, e a corregedoria lava as mãos

Corta, close no arregaço
}

\footnotetext{
4 Disponível em: http://www.geografia.seed.pr.gov.br/modules/noticias/article.php?storyid=119. Acesso em $26 \mathrm{de}$ set. 2020.
} 
Uma cadeira vazia, família faltando um pedaço

Dói no estômago, tipo azia

No âmago o espaço daquela piada que ele sempre fazia

Esses meninos são sangue, medo e pele

Onde viaturas são abre alas do IML

É, eu nem choro mais, pois bem

Não sei dizer se eu fiquei mais forte ou se eu morri também

$[\ldots]^{5}$

$\mathrm{Na}$ letra de "Canção pros meus amigos mortos", do rapper Emicida, do álbum Doozicabraba e a Revolução Silenciosa, de 2011, a situação descrita é bastante clara: a entrada da polícia em espaços periféricos é indicativo de violência e morte de jovens principalmente, resultando no choro de mães e em famílias enlutadas, enquanto isso não há nenhuma ação disciplinar ou investigativa da corregedoria em relação às ações policiais.

Podemos observar essa aproximação feita por Campos, que aponta a semelhança de tratamento dado a quilombos, favelas e modelos de ocupação dos subúrbios:

\begin{abstract}
Em larga medida, discutir favelas é falar também de preconceitos e discriminação que parte dos moradores de grandes centros urbanos tem com relação ao lugar $\mathrm{e}$ aos seus habitantes. [...] ficam evidentes tais procedimentos, pois desde sua origem, se se pensar em um processo, os lugares ocupados pelos mais pobres recebem pouca atenção do poder público no que se refere ao tamanho dos problemas sociais. Entretanto, como no passado, em sua versão anterior à República: o quilombo, a favela recebem uma atenção especial do aparelho policial, tendo em vista que favelas e favelados são considerados como um caso de polícia, mas não como um problema da sociedade (CAMPOS, 2013, s/p).
\end{abstract}

A organização dos grupos historicamente escravizados se deu através de resistência, sobretudo com disposições espaciais, políticas e econômicas, de uma forma bem peculiar e estratégica, como nos quilombos. Essa organização resgatava a historicidade, a cultura e os modos de viver de indivíduos que foram prisioneiros de uma elite agrária; entretanto, esses grupos foram criminalizados, simplesmente, por buscarem sua liberdade e perpetuarem suas raízes culturais (CAMPOS, 2013, s/p). Os quilombos podem ser descritos como organizações de lutas e de resistência, que mesclam múltiplas relações organizacionais, que são visualizadas sob novas óticas.

$\mathrm{Na}$ letra da canção de rap "Antigamente quilombo, hoje periferia", do álbum Z’África Brasil, de 2002, do grupo Z'África Brasil, fica evidente as tentativas forçadas de deslegitimar a cultura desses locais. 0 grupo faz uma aproximação transatlântica entre África e Brasil. A letra

${ }^{5}$ Disponivel em: https://www.youtube.com/watch?v=dl-M-EMcbdQ. Acesso em 30 de nov. de 2020. 
da canção carrega um teor de revolta e denúncia, fazendo relação direta entre quilombo e periferia:

A que sentido flores prometeram um mundo novo?

Favela viela morro tem de tudo um pouco,

Tentam alterar o DNA da maioria.

Rei Zumbi! Antigamente Quilombos Hoje Periferia!

Levante as caravelas aqui não daremos tréguas não, não

Então que venha a guerra

Zulu Z'Africa Zumbi aqui nâo daremos trèguas nâo, nâo

Entâo que venha a guerra

Sempre a mil aquì Z'Africa Brasil

Pra quem fingiu que não viu a cultura resistiu

Num faroeste de caboclos revolucionários

É o Z Zumbi que Zumbazido Zuabido Zumbizado

A lei da rua quem faz é você no proceder

Querer é poder, atitude é viver

Hoje centuplicarei o meu valor

Eliminando a dor que afeta o meu interior

Querem nos destruir mas não vão conseguir

Se aumentam a dosagem mas iremos resistir

Evoluir não se iludir com inimigo

Que transforma cidadão em bandido, perito em latrocínio.

Os hereditários sempre tiveram seus planos

Ao lado de uma par de dólar furado e falso e se encantam

É cadeira de balanço ou é cadeira elétrica

Gatilhos tiros na favela e o sangue escorre na viela

Um dia sonhei que um campinho da quebrada era uma fábrica da Taurus

Ainda bem que era um sonho e aì fiquei um pouco aliviado

Mas algo em meu pensamento dizia pra mim

Porra! Se na periferia ninguém fabrica arma

quem abastece isso aqui?

O sistema não está do lado da maioria

Já estive por aqui sei lá quantas vidas e continua a covardia,

Esquenta não, somos madeira que cupim não rói, a gente supera

todas as drogas e as armas que estão aqui

devolveremos em guerra

[...]

Zumbi, o redentor, agora o jogo virou, quilombos guerreou, periferia acordou

Cansamos de promessas, volta pro mato capitão

pois já estamos em guerra!!

[...]

Sugam da terra injetam no próprio homem

Alteram a natureza, Óleo no mar, fogo no monge

Jardins do éden, as flores tem cheiro de morte

Olhe o seu próprio COQUETEL MOLOTOV!

(Grifos nossos). ${ }^{6}$

${ }^{6}$ Disponivel em: https://www.youtube.com/watch?v=rmus6lQE57c. Acesso em 30 de nov. 2020. 
Após 132 anos da assinatura da lei Áurea, ainda temos as comunidades quilombolas que são espaços nos quais sujeitos vivenciam sua cultura de forma livre, servindo como refúgio. Esses espaços estão mais afastados do centro das cidades e das indústrias. Nessas organizações ainda perpetuam e se vivenciam a ancestralidade, os costumes, os saberes, dialetos e a cultura africana, que por muito tempo foram perseguidos e demonizados no Brasil. Sendo assim, podemos inferir que esses grupos quilombolas lutam diariamente para a manutenção de sua sobrevivência e da sua cultura, uma diáspora africana em terras brasileiras, mantendo aspectos culturais e identitários desses povos. Carril observa, nesse sentido, que

[...] os quilombos não se restringem ao período escravista. Vários agrupamentos de população negra foram identificados em distintas regiões brasileiras, sobretudo em lugares mais afastados dos centros urbanos e das regiões industrializadas do país, como lugares de refúgio. Muitos deles guardavam saberes tradicionais, manifestações culturais próprias como dialetos e relação específica com a natureza, bem como respeito a valores da ancestralidade pertinente à formação do grupo (CARRIL, 2006, p. 165).

As periferias urbanas brasileiras ${ }^{7}$ são compostas majoritariamente por uma camada social que luta diariamente para a manutenção de sua sobrevivência. Sujeitos que sobrevivem nesses espaços e enfrentam diariamente problemas relacionados à falta adequada de moradia, saneamento básico, educação pública, transporte, lazer e atendimento de saúde (OLIVEIRA; OLIVEIRA, 2019, p. 41), condicionando estes a uma vida precária:

\begin{abstract}
Fonte de estigma, de segregação e preconceito, a expressão "periferia" nos remete, por um lado, às áreas marcadas por problemas de segurança pública, roubos, assassinatos, tráfico de drogas, violência doméstica; e, por outro lado, à ideia da falta e de carência, como moradias inacabadas e/ou em área de risco, ausência de infraestrutura - ausência saneamento básico, arruamento irregular, problema de segurança alimentar e nutricional (OLIVEIRA, 2017). Tanto em uma quanto em outra imagem o termo periferia está carregado de fobias e de preconceitos. (OLIVEIRA; OLIVEIRA, 2019, p. 42)
\end{abstract}

Os meios de comunicação, inclusive as mídias televisivas, só dão visibilidade às periferias quando acontecem eventos relacionados à violência, omitindo, muitas vezes, que

\footnotetext{
${ }^{7}$ Quando nos referirmos, nesse trabalho, ao termo periferia estamos, pois, considerando todos os espaços sociais apartados do centro do poder decisório, como favelas e comunidades urbanas. Oliveira e Oliveira lembram que "A palavra margem e a palavra subúrbio, termos evidenciados pelo dicionário [quando consultada a palavra periferia], remetem-nos, respectivamente, as palavras marginais e suburbanos, ambas usadas, não raro, de forma pejorativa para designar posições de sujeitos (especialmente jovens negros) que residem em áreas periféricas dos espaços urbanos." (OLIVEIRA; OLIVEIRA, 2019, p. 43).
}

Revista de Ciências Humanas, Frederico Westphalen - RS, , v. 21, n.1, p. 63-85, jan./abr. 2020. 
naqueles espaços existe uma produção cultural vasta e plural, que é negada e invisibilizada pelas classes dominantes. Takeuti pontua que

Interessa, aqui, [ela se refere a seu artigo] ressaltar aspectos inventivos de vitalidade social que alcançam visibilidade, em nada insignificante, na sociedade brasileira, mesmo quando, ainda, amplas parcelas sociais dos diferentes segmentos dela (a mídia impressa e televisiva, por exemplo) só prefiram alardear o "avesso da periferia" (TAKEUTI, 2010, p. 14-15).

No trecho a seguir da letra da canção "Na fé irmão", do álbum Nada como um dia após o outro dia, de 2002, dos Racionais MCs, fica evidente a crítica direta sobre a mídia televisa e a impressa. Observamos uma oposição em relação à Rede Globo de televisão e a revista Veja, lidas como representes do mal.

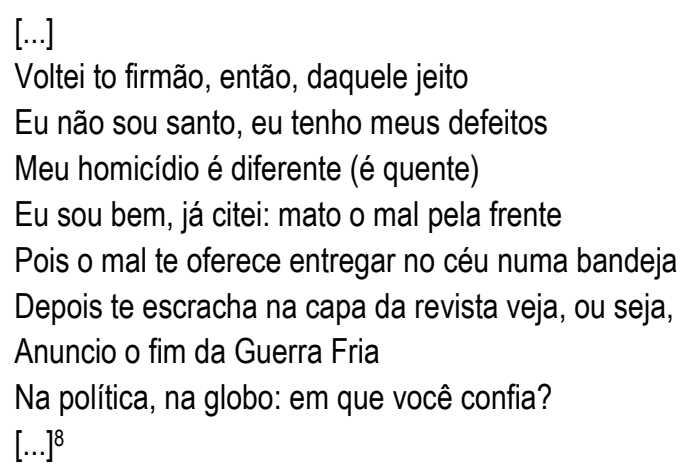

Uma letra de rap que deixa evidente o trabalho dos meios de comunicação em evidenciar a periferia de uma forma negativada é "Olha o Menino", de Negra Li e Heilão, do álbum Guerreiro, Guerreira, de 2005:

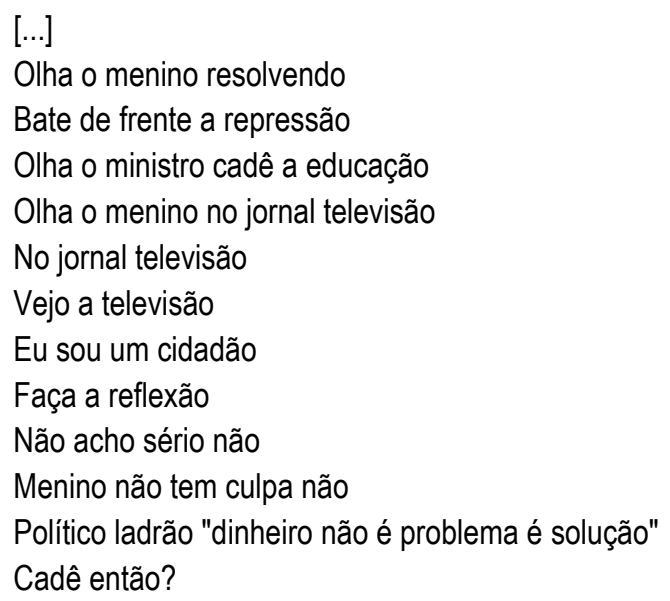

${ }^{8}$ Disponivel em: https://www.youtube.com/watch?v=xvSmplZpOgM. Acesso em 30 de nov. 2020. 
E quem te viu quem te vê, doidão

O que era cinco agora é dez é inflação

0 valor é cifrão

Por favor preste atenção

Aqui é Helião

Tamo no mesmo barco na mesma situação

Sou malucão a minha eu faço

E não tô por acaso

$[\ldots]^{9}$

Na letra, também vemos uma crítica à parte do setor político, qualificado de "políticos ladrão", como uma denúncia em relação à vida marginalizada e delinquente do menino periférico, sugerindo que o menino está na criminalidade por faltas de políticas públicas, principalmente ligadas à educação. Pensar em educação é pensar em libertação social e construção de uma autonomia que não é delegada, mas construída com criticidade e autonomia.

$\mathrm{Na}$ canção "Periferia é periferia (em qualquer lugar)", do álbum Sobrevivendo no inferno, de 1997, do grupo Racionais MCs, enfatiza-se cenas de violência que acontecem nesses espaços:

Esse lugar é um pesadelo periférico

$[\ldots]$

Ninguém vê sair, ninguém escuta chegar

O trabalho ocupa todo o seu tempo

Hora extra é necessário pro alimento

Uns reais a mais no salário

Esmola de patrão, cuzão milionário

[...]

Aqui a visão já não é tão bela

Não existe outro lugar - Periferia, gente pobre

[...]

Não existe outro lugar - Periferia é periferia!

$[\ldots]$

Outro maluco disse que ainda é embaçado

Quem não morreu, tá preso sossegado

[...]

"Mano, que treta, mano! Mó treta, você viu?

Roubaram o dinheiro daquele tio!"

Que se esforça sol a sol, sem descansar

Nossa Senhora o ilumine, nada vai faltar

É uma pena, um mês inteiro de trabalho

Jogado tudo dentro de um cachimbo, caralho

0 ódio toma conta de um trabalhador

Escravo urbano, um simples nordestino

$[\ldots]$

${ }_{9}^{9}$ Disponivel em: https://www.youtube.com/watch?v=GqT9BPWQBAQ. Acesso em 30 de nov. 2020. 


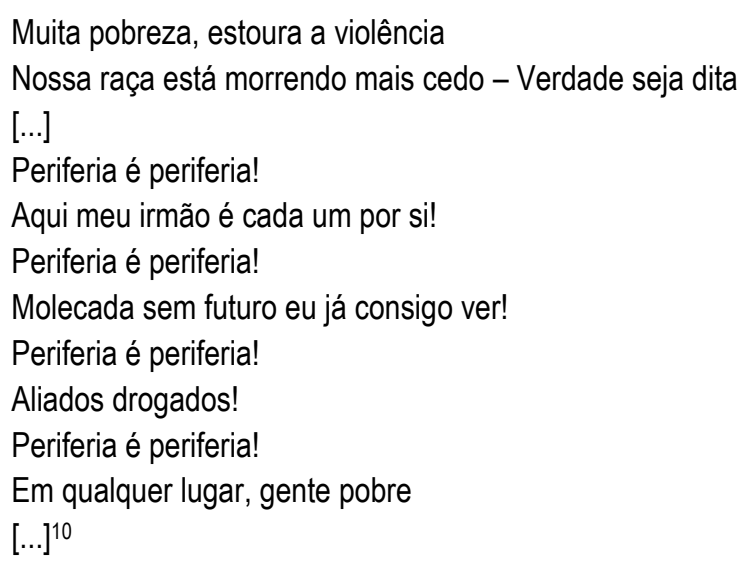

Ao dizerem que "periferia é periferia", entende-se que em qualquer lugar periférico as coisas são da mesma forma, há as mesmas demandas e os mesmos problemas. No entanto, não podemos observar esses espaços como mero lugares de produção de violência e mazelas, ainda que saibamos que esses fatos existam e estejam povoados nas canções de rap, como vemos na letra acima.

Por isso interpretar esses espaços se faz necessário, compreendendo a organização urbana em sua plenitude, não apenas por uma ótica, devemos enxergar de uma forma pluviversal. Ao mesmo tempo, podemos observar que as produções culturais desses espaços apontam para uma série de lacunas e denúncias quanto à negação dos direitos fundamentais que esses sujeitos sofrem diariamente.

Não podemos, pois, generalizar esses espaços como locais de apenas mazelas sociais; devemos compreender que ali existe saberes, múltiplas relações de cooperação, arte e cultura. Com base nos estudos de Takeuti, observamos mudanças significativas nos espaços urbanos brasileiros. A periferia ainda carrega uma visão cristalizada e estereotipada de lugar que produz "sujeira social", como tráfico, abandono, violação de direitos, delitos e múltiplas violências, mas esses conceitos engessados estão sendo desconstruídos e revistos. Os espaços periféricos vêm ganhando notoriedade devido às múltiplas produções, que são diversas (artísticas, culturais, esportivas), que muitas vezes chegam em outros espaços, transcendendo as fronteiras. Esse termo, que até então era depreciativo, começou a se ressignificar, pensando nas perspectivas culturais desses espaços:

[...] se, antes, a "periferia" era visível apenas como o lugar da infâmia (violências diversas, crimes, tráfico de drogas...), ela passou a expor também um cenário em que se disseminam inventividades artísticos literários-culturais-esportivos com

${ }^{10}$ Disponivel em: https://www.youtube.com/watch?v=vfbuiF5sXOM. Acesso em 30 de nov. 2020. 
produções que chegam a escoar para fora dela. Dir-se-ia que se trata de uma expressão de múltiplas singularidades em conexão, realizando movimentos em proliferação que efetivam ultrapassagens de fronteiras. [...] A arte popular parece produzir desdobramentos peculiares na subjetividade de seus habitantes, os quais passam a ter outras posturas diante das infindáveis dificuldades e dilemas produzidos pela insistente condição de pobreza e miséria. (TAKEUTI, 2010, p. 14)

O gênero musical rap, antes de tudo, é um uma narrativa poética musical política e, nessa perspectiva, as canções não só expõem o lado obscuro desses lugares, mas também narram o positivo e as potencialidades destes espaços. Bertelli destaca que tem havido uma

[...] desconstrução das leituras de periferia pautadas, analiticamente, pela negatividade descritiva e, politicamente, pelo intervencionismo centrista, propondo uma abordagem do rap que permita expor e discutir a positividade do potencial político presente na dinâmica e nas experiencias das periferias [...] (BERTELLI, 2017, p. 16, grifos do autor).

É possível pensar como essas narrativas poéticas ritmadas e rimadas constroem e desconstroem muitos conceitos que estão pré-estabelecidos em uma sociedade, que ainda não é sensível às culturas de massa e popular, como o rap, que dialoga com as duas culturas de forma direta.

A classe dominante direciona e reafirma o preconceito de que todos moradores de periferia são indivíduos de alta periculosidade. Podemos observar isso na letra da música "É o crime", de 2004, do álbum Tarja Preta, de Gog. 0 rapper relata que seu crime é representar as quebradas do Brasil, buscando melhores condições de vida para os moradores das favelas. Ao mesmo tempo Gog diz que valoriza a postura de quem suporta a vida dura:

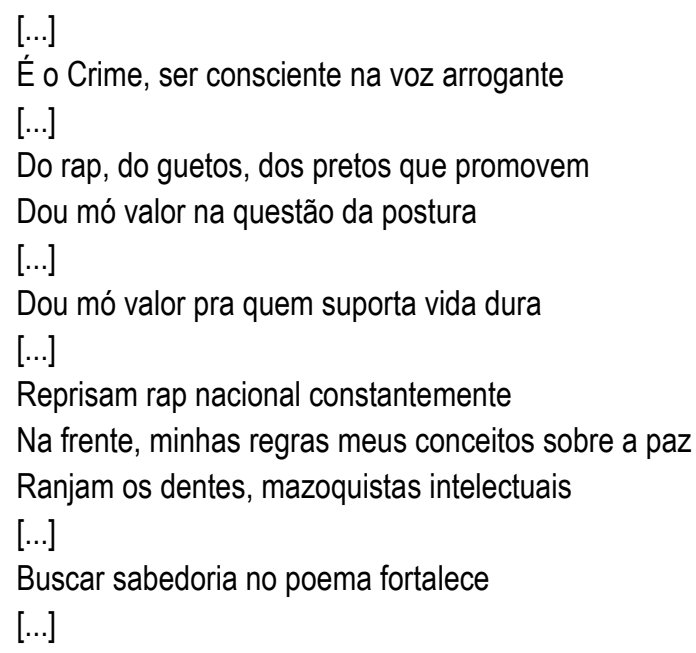


Rezo a prece, que leva o coração já quase morto

Alegria e alguns momentos de puro conforto

$[\ldots]$

Prego sem medo no alto pensamento

Que reflete 0 imenso poder das palavras

Que pra burguesia são malditas e macabras

Brutalidade é o pior do Supercine

Representa as quebradas do Brasil esse é meu crime

[...]

Então reflita, sobre seus conceitos

Então reflita, sobre seus direitos.

Então reflita, vem jogar no nosso time

$[\ldots]^{11}$

Se em outros tempos os sujeitos moradores das periferias não gostavam de ser designados como "sujeitos periféricos"; hoje, as coisas ganham uma nova dimensão e um remodelamento estético e político, visto que muitos se sentem pertencentes a esses espaços e tentam disseminar a arte e a cultura que ali são produzidos. Ressignificando o que é ser sujeito em uma periferia, esses indivíduos vão compreendendo seu papel social e político dentro desses espaços, fazendo valer sua cidadania. E o rap e a cultura hip hop têm muito a ver com essa nova forma de compreensão, conforme aponta Takeuti:

Em lugar de empunharem armas, vociferam seus cantos e poemas (o rap); rompem espaços urbanos apenas com seus corpos em danças rompantes (o break, o street dance); pintam muros ou paredes de edificações urbanas (o grafite); escrevem e publicam contos, poemas, romances e histórias de vida de "gente da periferia" e suas denúncias sociais (a literatura periférica) e; se organizam em pequenos núcleos de confabulação (a Posse) para reinventar uma nova forma de resistir e, consequentemente, de viver numa sociedade em que perduram relações violentas de desigualdade social. (TAKEUTI, 2010, p. 15)

Assim, avalia Takeuti, por meio da inserção dos jovens no movimento hip hop, haveria uma readequação ao conceito de periferia que, ainda que seja uma "condição geográfica", passa a ser entendida também como "um sentimento de pertencimento'." (TAKEUTI, 2010, p. 15).

Para D’Andrea (2013, p. 20), essa nova modulagem constrói um dado orgulho periférico, que se desenvolveu pelo nascimento de um fenômeno político chamado de "lulismo", relacionado à hegemonia exercida por um partido popular que tinha como pauta lutas populares, e pela emergência de presidente pobre, operário e nordestino. Essa construção política do

11 Disponível em: https://www.youtube.com/watch?v=hl7790-bBJQ. Acesso em 30 de nov. 2020. 
"sujeito periférico" alia-se a um discurso, portanto, de defesa dos direitos dos pobres e periféricos:

[...] no momento em que a população periférica passa de uma leitura estigmatizante de si próprio a um de colocar-se no mundo de maneira afirmativa, criou-se uma situação social que ajudava a fomentar ao mesmo tempo em que dialogava com 0 fenômeno social chamado lulismo. Se Mano Brown passou toda sua carreira artística incentivando jovens da periferia a agirem e acreditarem no seu próprio potencial, não nos esqueçamos que Lula afirmou em seu discurso na Avenida Paulista, quando havia ganhado as eleições presidenciais de 2002, que: "nunca duvide da força da classe trabalhadora brasileira" (D' ANDREA, 2013, p. 110-111, itálico da autora).

Ser "sujeito periférico" é uma construção social, muitas vezes subjetiva, que se dá de forma constante e passível de mudanças e só "corre quando essa subjetividade é utilizada politicamente, com organizações coletivas e ações públicas". (D'ANDREA, 2013, p. 15). Compreender o termo sujeito periférico é complexo e importante, tendo em vista que este termo está atravessado e permeado por múltiplas subjetividades. Assim, pode-se pensar por um viés interpretativo geral que sujeito periférico está sob condições de exclusão de direitos fundamentais, mas existem outras formas de se pensar e se apropriar deste termo, compreendendo essa palavra por outras óticas e contextos:

[...] sujeito periférico poderia ser intercambiado por pessoa periférica. Este significado pode deslizar para outro atributo parecido, como se observará no significado a ser discutido a seguir (sic). Sujeito como 'subjetividade' - para além de designar uma pessoa ou indivíduo, designa que a dimensão externa representada por este enquanto 'existência' está preenchida de elementos intangíveis que o constituem, mas derivada de uma experiencia compartilhada e mutualmente reconhecida [...]. Estes elementos seriam normas, formas de ver, sentidos, sentimentos, idiossincrasias e particularidades que formariam uma determinada subjetividade. Neste caso, sujeito periférico poderia ser traduzido subjetividade periférica, que de fato caberia na formulação que aqui se propõe, ou seja, ser portador de elementos cognoscentes constituídos por sua posição periférica. Aqui a palavra subjetividade por si só define aquilo que vem complementado pelo adjetivo periférico, existindo com certa independência em relação a este. (D' ANDREA, 2013, p. 172, itálicos do autor)

Entendemos que o sujeito periférico está dentro de um grupo minoritário - "minoria", de forma qualitativa. Entretanto, podemos pensar que nem todas minorias são compreendidas como sujeitos periféricos, tendo em vista que existem grupos específicos dentro dos grupos 
minoritários que muitas vezes desconhece o que é ser sujeito periférico e não vivencia a realidade da vida periférica (de favelas e aglomerados).

Falar em grupos minoritários ou minorias é um paradoxo, tendo em vista que esses sujeitos que são considerados minorias, na realidade, são a maioria em termo populacional. 0 conceito de minoridade remete à democracia representativa. Todavia, a democracia é um regime qualitativo porque no processo democrático a minoria pode ser ouvida. Logo, minoria é uma voz qualitativa para designar uma carência de voz afirmativa de segmentos das classes econômicas subalternas. Assim, ao falarmos de minorias ou grupos minoritários podemos inferir sobre uma parcela majoritária da população que possui, no entanto, demandas especificas e carece de políticas públicas que visem efetivar seus direitos fundamentais e também proteção social. São cidadãos comprometidos com lutas sociais em diversas modalidades, compostos por homossexuais, mulheres, povos indígenas, ambientalistas, negros, etc. Esses grupos são movidos, como aponta Muniz Sodré, por um impulso de transformação e de uma organização que possui pretensão ético-política dentro de uma luta conta-hegemônica (Cf. SODRÉ, 2005, p. 12).

Sodré mobiliza quatro características fundamentais para que se possa compreender 0 conceito de minoria: a vulnerabilidade jurídico-social; a identidade in statu nascendi; a luta contra-hegemônica; as estratégias discursivas. Em relação à primeira, ele explica que se refere ao estado de vulnerabilidade de certos grupos sociais, "diante da legitimidade institucional e diante das políticas públicas. Donde sua luta por uma voz, isto é, pelo reconhecimento societário de seu discurso" (SODRÉ, 2005, p. 13). A segunda observa que "Do ponto de vista de sua identificação social, a minoria apresenta-se [...] na condição de uma entidade em formação que se alimenta da força e do ânimo dos estados nascentes" (SODRE, 2005, p. 13).

De acordo com as duas primeiras características, surge a terceira, que afirma que "Uma minoria luta pela redução do poder hegemônico", fazendo das da "mídia [...] um dos principais 'territórios' dessa luta”. (SODRÉ, 2005, p. 13). A última característica aponta que esses grupos se utilizam de "Estratégias de discurso e de ações demonstrativas", tais como "passeatas, invasões episódicas, gestos simbólicos, manifestos, revistas, jornais, programas de televisão, campanhas pela internet" (SODRÉ, 2005, p. 13).

Young observa, a respeito da sub-representação de grupos sociais, que

[...] são muito frequentes as queixas que apontam o caráter excludente das normas de representação. As pessoas muitas vezes reclamam que os grupos sociais dos quais fazem parte ou com os quais têm afinidade não são devidamente 
representados nos organismos influentes de discussões e tomadas de decisão, tais como legislaturas, comissões e conselhos, assim como nas respectivas coberturas dos meios de comunicação. Essas demandas evidenciam que numa sociedade ampla e com muitas questões complexas os representantes formais e informais canalizam a influência que as pessoas podem exercer. (YOUNG, 2006, p. 140)

Falar em democracia é pensar em inclusão política, principalmente no que se refere a uma maior representatividade desses grupos sub-representados, ainda mais quando estes são maioria ou estão submetidos a desigualdades estruturais. É importante e emergencial os sujeitos desses grupos ocuparem espaços de tomada de decisões, tendo em vista que estes lugares ainda são destinados de uma forma majoritária a homens, brancos, de classes média e alta e heterossexuais, que quase sempre não atendem às demandas de determinados grupos. Young aponta que

\footnotetext{
Uma forma importante de promover maior inclusão de membros dos grupos sociais sub-representados se dá por meio de dispositivos políticos destinados especificamente a aumentar a representação de mulheres, pessoas da classe trabalhadora, minorias raciais ou étnicas, castas desfavorecidas etc. Assim, esquemas como cotas em listas partidárias, representação proporcional, cadeiras parlamentares reservadas e delimitação de distritos eleitorais especiais, entre outros, têm sido propostos e implementados para promover a representação de grupos. (YOUNG, 2006, p. 170)
}

Os movimentos sociais estão ligados a essas questões de forma direta, uma vez que demandam e cobram formas plurais de representações em empresas privadas, órgãos estatais, comissões, conselhos e em instâncias diretivas. Entretanto, muitas sociedades ainda reafirmam as exclusões estruturais, promovendo um processo de segregação.

Os grupos minoritários precisam deixar a margem e conquistar esses espaços de poder que sempre foram negados a eles, não prevendo suas existências. Assim, 0 ato de ocupar esses espaços é um ato político de re(existir) a uma sociedade que nega diariamente os direitos a determinados grupos, deixando esses indivíduos em uma situação de precariedade e isolamento. Conforme observa Righi: "É nesse contexto que são chamadas 'minorias', estereotipadas e invisíveis aos olhos do poder instituído e da sociedade, as quais para 'se proteger', são forçadas a se fechar ainda mais em seus guetos, dentro de projetos indenitários de 'resistência' [...]". (RIGHI, 2011, p. 23).

O gênero musical rap aproxima e dialoga com as múltiplas subjetividades dos grupos minoritários através de suas canções. Observamos canções de cunho denunciativo em relação a 
uma sociedade conservadora e elitista, que ainda seleciona e exclui determinados indivíduos que não se encaixam em um modelo predeterminado por uma cultura eurocêntrica. Assim, podemos pensar a cultura hip hop e o rap como instrumentos de inclusão social - o que ressalta sua importância no espaço escolar. Teperman aponta, nesse sentido, que

[...] a capacidade de mobilização do rap passou a interessar grupos que, até então, havia tido espaço reduzido no campo. Mais e mais, "minorias" como mulheres, indígenas e homossexuais vem encontrando espaço de expressão como rappers, inserindo novas reinvindicações na pauta e propondo novas elaborações estéticas [...] (TEPERMAN, 2015, s/p.)

Esses grupos segregados usam de artefatos para resistir e, nesse panorama, organizam de forma política espaços que sejam democráticos, que permitam a pluralidade estética e de pensamentos para promover uma sociabilidade que englobe o maior número de sujeitos. Essa estrutura traz uma organização que aproxima esses indivíduos segregados:

[...] a relativa interdição aos canais institucionais de participação e representação política, assim como a intolerância - velada ou ostensiva - ao desempenho de certas atividades e à ocupação de certos espaços urbanos, conduziu essa articulação de um sentido coletivo da experiencia para esferas que o debate público usualmente associa ao lazer e ao divertimento, quando não à baderna e à libidinagem. (BERTELLI, 2017, p. 13, itálicos do autor)

Para Bertelli, esse modo de organização pode ser compreendido a partir da relevância que "a expressividade estética assume na sociabilidade das camadas pobres urbanas", fazendo com que "Canções, vestimentas, pichações, vídeos e posts em redes sociais, com todos os aspectos de oralidade e narrativas que encerram, com todo o repertório de códigos, gestos e comportamentos" sejam abordados "como agenciamento coletivo de articulação de sentido às virtuais comunidades políticas que se configuram nas dinâmicas sociais das camadas marginalizadas da sociedade brasileira". (BERTELLI, 2017, p. 13-14).

Assim, o sujeito periférico, ainda que morador de espaços marginalizados pelo/em relação ao centro, entendido este como lugar de decisões e de representação política, assume sua condição de produtor/consumidor de cultura, não designando o termo periferia apenas “'pobreza e violência' - como até então ocorria no discurso oficial acadêmico -, mas também 'cultura e potência', confrontando a lógica genocida do Estado por meio da elaboração coletiva de outros modos de dizer" (OLIVEIRA, 2018, p. 23). 


\section{CONSIDERAÇÕES FINAIS}

As letras de rap podem ser comparadas a documentos que mostram a realidade de uma determinada época, fazendo uma reflexão sobre esta, promovendo remodelamentos de condutas que se transformam em uma história cultural e social. Pode ser visto, portanto, como "como uma arte manifestamente política", que expressa as vozes de pessoas silenciadas e submetidas à opressão, "que leva a um público maior uma perspectiva mais concreta e crítica da realidade vivida pelas pessoas marginalizadas", sendo o gênero musical fundamental "em tempos de intolerância e de negação da opressão". (OLIVEIRA, 2020, p. 23-24).

Tal perspectiva, como vemos, se alinha aos fundamentos essenciais da educação em direitos humanos, na medida em que o rap promove a ideia de transformação social, a partir da valorização e visibilidade de grupos excluídos das esferas de poder. (Cf. MAGENDZO, 2016, p. 221).

Por isso, defendemos, neste artigo, que o rap (e toda a dimensão política dele) seja discutido no espaço escolar, visto ser um gênero poético-musical originário de territórios periféricos, construído por meio das vivências, histórias e saberes de sujeitos marginalizados, conferindo voz/poder a pessoas historicamente silenciadas. Dessa foram, estaremos acionando competências gerais importantes da BNCC, referentes ao respeito à diversidade social e de saberes, ao exercício da empatia e da solidariedade e à responsabilidade e cidadania. As próprias Diretrizes Curriculares Nacionais da Educação Básica asseveram a participação desses saberes outros no espaço escolar, quando apontam que

\footnotetext{
A educação destina-se a múltiplos sujeitos e tem como objetivo a troca de saberes, a socialização e o confronto do conhecimento, segundo diferentes abordagens, exercidas por pessoas de diferentes condições físicas, sensoriais, intelectuais e emocionais, classes sociais, crenças, etnias, gêneros, origens, contextos socioculturais, e da cidade, do campo e de aldeias. Por isso, é preciso fazer da escola a instituição acolhedora, inclusiva, pois essa é uma opção "transgressora", porque rompe com a ilusão da homogeneidade e provoca, quase sempre, uma espécie de crise de identidade institucional. (BRASIL, 2003, p. 25)
} 
O rap, como manifestação cultural originária desses espaços, promove, assim, um debate sobre opressões e violências, ao mesmo tempo que se age como agente transformador da realidade de seus praticantes, na medida que são entendidos com produtores de arte.

\section{REFERÊNCIAS}

ALTHUSSER, Louis. Ideologia e aparelhos ideológicos do estado. Trad. Joaquim José de Moura Ramos. Lisboa: Editorial Presença, 1980.

BARROSO, João. Factores organizacionais da exclusão escolar: a inclusão exclusiva. In RODRIGUES, David (org.). Perspectivas sobre a inclusão: da educação à sociedade. Porto: Porto Editora, 2003.

BERTELLI, Giordano Barbin, Introdução. In: BERTELLI, Giordano Barbin; FELTRAN, Gabriel (org.). Vozes à margem: periferias, estética e política. EdUFSCar, 2017.

BRASIL. Base Nacional Comum Curricular. Brasília: MEC, 2018. Disponível em: http://basenacionalcomum.mec.gov.br/abase/ Acesso em: 19 de nov. 2019.

BRASIL. Diretrizes Curriculares Nacionais da Educação Básica. Brasília: MEC/SEF, 2003. Disponivel em:

http://portal.mec.gov.br/index.php?option=com_docman\&view=download\&alias=13448-diretrizescuriculares-nacionais-2013-pdf\&ltemid=30192. Acesso em 10 de fev. 2021.

BRASIL. Parecer 15/1998. Brasília: MEC/CNE, 1998. Disponível em: http://portal.mec.gov.br/cne/arquivos/pdf/1998/pceb015_98.pdf. Acesso em 10 de fev. 2020.

CAMPOS, Andrelino. Quilombos, favelas e os modelos de ocupação dos subúrbios: algumas reflexões sobre a expansão urbanas sob a ótica dos grupos segregados. Núcleo Piratininga de educação, 2013. Disponível em: <https://nucleopiratininga.org.br/quilombos-favelas-e-osmodelos-de-ocupacao-dos-suburbios-algumas-reflexoes-sobre-a-expansao-urbanas-sob-a-oticados-grupos-segregados/>. Acesso em: 05 de out. 2020

CARRIL, Lourdes de Fátima Bezerra. Quilombo, território e geografia. Agrária, São Paulo, n. 3 , p. 156-171, 2005. Disponível em: https://www.revistas.usp.br/agraria/article/view/92/91>. Acesso em 05 de out. 2020

D’ANDREA, Tiarajú Pablo. A formação dos sujeitos periféricos: cultura e política na periferia de São Paulo. 2013. Tese de Doutorado (Doutorado em Sociologia). Universidade de São Paulo. Disponível em:< https://pdfs.semanticscholar.org/8e0d/0df0e5db70cf8725ecbf04e63894852074b7.pdf> Acesso em: 15 de set. 2020.

HOLLANDA, Heloisa Buarque de. Estética da periferia: um conceito capcioso. 2012. Disponível em: <http://docplayer.com.br/11177751-Estetica-da-periferia-um-conceito-capcioso-heloisabuarque-de-hollanda-coordenadora-do-programa-avancado-de-cultura-contemporaneaufrj.html>. Acesso em: 08 dez. 2019. 
LOUREIRO, Bráulio. Autoeducação e formação política no ativismo de rappers brasileiros. 2015. (216 p.). Tese (doutorado) - Universidade Estadual de Campinas, Instituto de Filosofia e Ciências Humanas, Campinas, SP. Disponível em: <http://www.repositorio.unicamp.br/handle/REPOSIP/281155>. Acesso em: 24 de set. 2020.

MAGENDZO, Abraham. La Educación en Derechos Humanos y la Justicia Social en Educación. RODINO, Ana Maria et al. (org.). Cultura e educação em direitos humanos na América Latina. Brasil: trajetórias, desafios e perspectivas, João Pessoa: CCTA, 2016.

OLIVEIRA, Acaum Silvério de. Sobrevivendo no inferno / Racionais MC's. São Paulo: Companhia das letras, 2018.

OLIVEIRA, Heli Sabino de; OLIVEIRA, Elaine Ferreira Rezende de. Juventudes, Periferias e o debate teórico acerca dessa temática no campo da educação. Ensaios Filosóficos, Rio de Janeiro, Volume XIX, p. 37-54, 2019. Disponível em:

http://www.ensaiosfilosoficos.com.br/Artigos/Artig019/04_OLIVEIRA_Ensaios_Filosoficos_Volum e_XIX.pdf. Acesso em 26 de set. 2020.

OLIVEIRA, Icaro. "Universo em crise": engajamento e denúncia no rap de Djonga. 2020. (112 p.) Dissertação (Mestrado) - Universidade Vale do Rio Verde, Mestrado em Letras, Três Corações, MG. Disponível em: https://www.unincor.br/images/imagens/2020/dissertacao-icarooliveira.pdf. Acesso em 20 de dez. 2020.

PELLEGRINI, Tânia. As vozes da violência na cultura brasileira contemporânea. Crítica marxista, Campinas, v. 21, p. 132-153, 2005. Disponível em:

$<$ https://www.ifch.unicamp.br/criticamarxista/arquivos_biblioteca/artigo124critica21-Apelegrini.pdf>. Acesso: 28 ago. 2020.

RABENHORST, Eduardo. O que são Direitos Humanos? In: SILVEIRA; Rosa Maria Godoy; DIAS, Adelaide Alves; FERREIRA, Lúcia de Fátima Guerra; FEITOSA, Maria Luíza Pereira de Alencar Mayer; ZENAIDE, Maria de Nazaré Tavares (Org.). Educação em Direitos Humanos: fundamentos teórico-metodológicos. João Pessoa: Editora Universitária/UFPB, 2007. Disponível em: http://www.dhnet.org.br/dados/livros/edh/br/fundamentos/index.htm. Acesso em 20 de mar. 2020.

RIGHI, Volnei José. RAP, ritmo e poesia: construção identitária do negro no imaginário do RAP brasileiro. 2011. 515 f., il. Tese (Doutorado em Literatura). Disponível em < https://repositorio.unb.br/bitstream/10482/10853/1/2011_VolneiJoseRighi.pdf>. Acesso em 23 de set. 2020

SILVA, José Carlos Gomes da. Arte e educação: a experiência do movimento hip hop paulistano. In: ANDRADE, Elaine (org.). Rap e Educação; Rap é Educação. São Paulo: Selo Negro, 1999.

SODRÉ, Muniz. Por um conceito de minoria. In: PAIVA, Raquel; BARBALHO, Alexandre (org.). Comunicação e cultura das minorias. São Paulo: Paulus, 2005.

TAKEUTI, Norma Missae. Refazendo a margem pela arte e política. Nómadas, Rio Grande do Norte, n. 32, p. 13-25, 2010. Disponível em: <

https://dialnet.unirioja.es/servlet/articulo?codigo=5484359>. Acesso em: 22 de set. 2020 
TEPERMAN, Ricardo. Se liga no som: as transformações do rap no Brasil. São Paulo: Companhia das Letras, 2015.

UNESCO. Programa Mundial para educação em direitos humanos. Nova York; Genebra, 2006. Disponível em:

http://www.dhnet.org.br/dados/textos/edh/br/plano_acao_programa_mundial_edh_pt.pdf. Acesso em 10 de mar. 2020.

YOUNG, Iris Marion. Representação política, identidade e minorias. Lua Nova, São Paulo, n. 67, p. 139-190, 2006. Disponível em: <https://www.scielo.br/pdf//n/n67/a06n67.pdf/> Acesso em: 23 de set. 2020. 